\title{
The Main Paradigms of Creative Management in the Aspect of Modern Cognitive Economy
}

\author{
Irina Lyskova \\ Economics and management department \\ Komi Republic Academy of State Service and Administration \\ Syktyvkar, Russia
}

\begin{abstract}
The article actualizes some problems of modern human resources management in the context of cognitive economy, states the role of human resources in modern business processes and in socio-economic and socio-cultural development of an organization. It emphasizes the significance of organizational culture, reveals the essence of creative management in the aspect of corporate culture development, improvement of modern business processes and perfection of self-management system.
\end{abstract}

Keywords-organization; human resources management; self-management; creative management; cognitive management; cognitive economy; organizational culture

\section{INTRODUCTION}

Managing a modern organization is a complex process that requires in-depth analysis of political, socio-economic, socio-cultural, socio-psychological and other factors, which determine risks, and unpredictability of the processes both in and out of an organization. Among the most significant factors affecting the internal organizational environment and the nature of today's business processes the following ones can be mentioned: continuous growth of knowledge, the specifics of human behavior in organization, involvement in professional activity, growing role of motivation to work, quality of communications in fast developing information technologies conditions, effectiveness of management decisions, recognizing the value of synergetic effect of organizational leadership and team technologies implementation $[2 ; 3 ; 19 ; 20 ; 23]$.

The modern socio-economic conditions of business development is impossible to overestimate organizational competitiveness, high adaptability of an organization, desire to improve business processes by focusing on the growing demands of customers for the quality of the offered goods and services. Intellectual potential that largely determines the quality of human resources of an organization can be considered one of the most important tools to facilitate high competitiveness $[1 ; 10 ; 23]$. Evaluating the quality of human resources we can refer to the human potential development index. It is integration indicator, which includes factors of well-being of the population (GDP per capita), the factors determining health status (life expectancy and real longevity) and educational level of the population. With regard to Russia, the picture is rather contradictory. As for the first two components of the index of human potential development, they require to be thoroughly worked at. Concerning the third component, the situation is even more difficult. In general, education indicators of the population of Russia correspond to the level of the most developed countries of the world, whereas in terms of efficient use of human resources there are serious problems: employment and demand for professionals, low wages, the crisis of labor motivation, lack of social security, the poverty of the working population, etc.

Nevertheless, education and professional qualification is a powerful source of economic development of the state, region, organization, business processes quality. Today there is a growing need to increase the effectiveness of knowledge management both at the individual and collective level. It is required to rethink the process of knowledge management, expand the capacity of the organization by improving the continuous professional development motivation system and staff training, improve the level of general and professional culture, the consolidate new models of organizational behavior, focused on high quality of modern business processes and quality management. Innovative development of organization presupposes development of the knowledge management strategy, summarizing the experience of successful companies, improving organizational culture in the aspect of knowledge value recognition, continuous intellectual and moral progress of an individual, forming an innovative model of employee's behavior, particularly in terms of taking initiative in the sphere of professional activity, developing professional competencies, selfeducation, etc. It is clear that cognitive and creative management are to ensure economic growth and life quality improvement of modern society $[4 ; 5]$. We shall also note that the knowledge economy (cognitive economy) received official recognition as a government strategy in several countries, e.g. in USA, Japan, China, Sweden, Switzerland, Germany, etc.

\section{BASIC CONCEPTS OF KNOWLEDGE MANAGEMENT}

It is commonly assumed that the concept of knowledge management as a system of intellectual organization's assets management originated in the early 90 s of the XX century. Among the causes of the origin of this concept it is possible to recognize the following processes: 
- the processes of globalization, focused on integration of various aspects of political, socio-economic, sociocultural life of the global community. In terms of economy, integration processes increasingly span the sphere of organization of work, finance, development of production and trade, improvements in information and communication technologies, formation and development of human resources. However, there is increasing competition taking place, which makes many organizations look for competitive advantages. In the pursuit of profit organizations sometimes don't take care of their reputation, often ignore the importance of social responsibility of business as well as the value and role of human resources.

- the rapid development of information technologies implementation of innovations that ensure high production rates, productivity enhancement, highquality processes upgrading, including the process of human resource management, quality of human resources;

- increasing technological level of production, computerization, robotics, aimed at the displacement of manual labor, development of resource-saving technologies, providing security and safety.

In the theory of cognitive management it is possible to single out a number of approaches to characterize knowledge. Knowledge can be viewed as a resource, asset, property, as a virtual matter.

Knowledge in the aspect of organizational development can be characterized as a set of personal skills, cultural and professional competencies of a worker, which they acquire in the process of training, education and development in the field of professional activity. These competences provide organizations with the effectiveness of individual and team work. From the point of view of the process approach to knowledge it is necessary to focus on knowledge as a value, especially in the personal sense; knowledge as a continuous process; knowledge as a system; and knowledge as a result. The system of organizational knowledge is formed by the total of development strategy of the organization; scientific bases of production organizing; practical application of scientific knowledge in a specific field of professional activity; organizational culture as a powerful factor of effective production and adaptation to market economy conditions. Accordingly, the concept of knowledge management is based on transformation of individual knowledge and competencies into the system of intellectual potential and intellectual capital of an organization, which forms the basis of the strategic and tactics development of an organization in the current socio-economic situation.

We should also note that the process of knowledge management in an organization implies the allocation of the following functions:

- motivation to acquire knowledge, primarily at the individual level, that provides ability to generate ideas;
- formalization of knowledge involving processing of data according to the requirements, rules, procedures, etc.;

- preservation of knowledge through various media;

- spreading (diffusing) knowledge by means of improving information technologies and organizational communications;

- application of knowledge through effective management solutions, quality business processes of an organization;

- accumulation of knowledge aimed to ensure organizational adaptation to factors of internal and external environment, provide organizational competitiveness in the modern socio-economic conditions;

- control of knowledge in accordance with the structure, content, aims and directions in development of an organization;

- upgrading knowledge according to individual and organizational needs.

\section{REENGINEERING AS A CREATIVE PROCESS}

The concept of knowledge management can be viewed in the context of the theory of business processes reengineering. Reengineering is characterized as one of the modern trends in the theory and practice of management which was founded in 1990s and designed to ensure high efficiency of business processes of an organization. M. Hammer and D. Champy are thought to be the authors of the concept of reengineering (or reconstruction of business processes) [12]. Reengineering involves the focus on improving key performance indicators of an organization through in-depth analysis, modeling and redesigning business processes. Reengineering of business processes is correlated with achievement of significant, abrupt, dramatic improvements in key performance indicators of an organization. The authors of the concept define reengineering as "the revision of business processes at a fundamental level and their radical reconstruction to achieve significant improvements in such important performance indicators as quality, service and speed" [10, p. 302].

Reengineering involves changing the basic principles of an organization. Here we shall highlight some of reengineering principles:

- the principle of rational organization of business processes that presupposes combining several activities into one process;

- the principle of democracy, characterized by employees' involvement of in decision-making;

- the principle of delegating authority, providing the speed of decision-making; 
- the principle of variability, which presupposes the chance of alternatives in business processes implementation;

- the principle of the validity of business processes reengineering;

- the principle of economic feasibility of controlling;

- the principle of succession and cyclic process of redesigning, etc.

The reconstruction of business processes itself includes a standardized data cycle, comprising the following steps:

- 1. Coordination of the reconstruction process with organizational strategy.

- 2. Analysis of the nature of existing business processes, aimed to identify their purpose and understand the opportunities for improvement and efficiency.

- 3. Defining of a set of improved processes that provide added value, both in combination with other processes.

- 4. Implementation of improving processes and their monitoring.

- 5. Start of a new cycle of business processes improvement.

Prospects and strategic plans of an organization justify the significance of introducing new approaches to the theory and practice of management. In practical terms, reengineering is most useful for organizations that are in crisis or close. Such circumstances are often caused by environmental factors, and, accordingly, the reconstruction process is seen as an inevitable measure. Conversely, it may be also suitable for organizations with a leading position aimed at rapid growth and stable competitive advantages.

It is necessary to mention the importance of social aspects of the reengineering process. Special attention should be paid to reengineering of human resources, including the process of labor motivation $[6 ; 18 ; 19]$.

Today there is acute need of new directions and approaches to the process of human resource management, development of existential, cognitive, creative, personal management in particular $[2 ; 14 ; 15 ; 16 ; 17 ; 18]$. In the process of reengineering of human resources it is necessary to sign out the competence-based, cognitive, existential and axiological approaches. These approaches substantiate the special importance of personal and professional goals and values, understanding life experience, possibilities of selfrealization in the sphere of professional activity.

One of the problem tasks of reengineering of human resources is the need to create proper conditions for realization of innovative potential of employees and formation of qualitative characteristics of a personality, which contribute to creating and implementing innovations. This process involves the importance of continuing intellectual development, conscious need to acquire new knowledge, develop professional competencies, motivation system improvement, and above all, self-motivation of labor activity, human desire for self-actualization, self-realization in professional activity, etc.

In the system of reengineering, they highlight cognitive reengineering as a radical change in the current structure of management and production in an organization, using cognitive approaches (cognitive modeling of the situation). The goal of cognitive reengineering is recognized as making business at modern high-tech level, forming learning, flexible and adaptive organization that creates, acquires, transfers and keep knowledge, and is able to change behavior in response to new knowledge, information, suggestions.

What's more reengineering should not be associated with process of improvement and quality management. There is fundamental difference between the processes of reengineering and quality management: reengineering involves replacing of the existing processes with new ones, whereas the quality management process is aimed at improving the business processes of an organization. A unique example of continuous improvement of organizational processes is the Japanese model of Kaizen.

\section{KAIZEN AS THE PhILOSOPHY OF CREATIVITY}

Kaizen philosophy is characterized as a basic concept of Eastern, particularly Japanese management. Kaizen is a continuous improvement process where all the participants of organizational activity are included. Kaizen philosophy reflects the essence of fundamental difference between the Eastern model of management and the Western one. A major distinguishing characteristic of Kaizen in comparison with the Western model of management is the fact that the Kaizen approach and the inherent to it thinking are process oriented, while the Western model of management prioritizes innovation and focus on results. Kaizen of industrial relations is characterized by the employees' specific style of thinking. This specific style of thinking is able to ensure success not only to Japanese companies. The philosophy and practice of Kaizen can be considered the modern concept of effective management [11].

The main objective of Kaizen is the desire to improve contemporary business processes. According to the concept of Kaizen all the effort of an organization should be directed to satisfy the needs and serve customers. Accordingly, Kaizen is a strategy of improvement, focused on the consumer. In addition, Kaizen creates a unique way of thinking - process oriented (process thinking). Used in Japan almost everywhere, and widely known in other Eastern countries the philosophy of Kaizen gives amazing results of improvement process, which is primarily focused on customer satisfaction, improving cost, quality and discipline of deliveries. The main philosophical idea of Kaizen reflects the very model of attitude to life, forming a special lifestyle and quality of life in relation to professional and social activity, family and personal life, which deserve to be continuously improved.

There are some features typical for the Japanese model of management: the continuous improvement in productivity, a 
wide range of measures to ensure universal quality control, improvement of labor relations, robotics, automation, high labor discipline, general maintenance of the equipment, the effectiveness of small group work, on-time delivery, development of cooperation, development of new products, etc. All that provides endless opportunities to improve processes and quality of performance. Kaizen generates process oriented thinking, actualizing such a position that to obtain better results, it is necessary to improve processes, including technological, organizational, managerial ones. From the point of view of forming effective management model, special attention is paid to a man's attitude to work, their desire to improve the process.

The process-oriented management system emphasizes such characteristics as discipline, time management, skills development, participation and involvement, morale, and communications. The high quality of the marked characteristics of industrial relations allows to bridge the gap between process and result, between goals and means, between tasks and indicators, allows employees to develop personally and professionally.

\section{The Essence of CREative Management}

In the current socio-economic situation the topics related to increasing personal effectiveness, improving practice of using powerful tools of personality development, maximizing the efficiency of organizational business processes are of considerable interest, both at individual and at organizational management level. The modern manager should give considerable attention to rethinking and understanding the role of human resources in production processes, realizing man's ability to produce new knowledge, not only on the basis of critical and analytical but also creative thinking. $[7 ; 8 ; 9 ; 13]$.

Nowadays it is not permitted to ignore human value as a rich innovative resource in the aspect of economic, social and cultural development of an organization. The importance of creativity and creative abilities of employees in the sphere of professional activity is determined by the particularly acute need for a high degree of adaptability of an organization to different changes in external environment, by desire for continuous competitiveness of an organization, which is associated with the need to survive in the modern information society, where much depends on the speed of information processing, formation and practical implementation of new knowledge in production processes $[21 ; 22]$.

Today in the basis of success and competitiveness of any organization there is ability of its employees to constantly evolve, acquire new knowledge, improve professional qualifications and skills, to provide high level of personal motivation for continuous performance improvement in all the spheres of human activity, including professional sphere. One of the indisputable achievements of modern personal management is the idea about the value of spiritual culture, awareness of primacy, priority and direction of the changes from the inside to the outside world $[7 ; 8]$.
The process of creative personal development, including personal, existential, cognitive and creative management is determined by the specificity of intellectual work, a person's ability to create new hypotheses, generate original ideas, set goals, identify the most efficient and effective ways to achieve them. One of the most significant characteristics in the system of cognitive and creative management is the ability of a man to organize, analyze, structure the information, refuse to reproduce patterns of thought, use formulaic, stereotypical approaches to solve professional tasks. In modern conditions there is a focus on the intellectual creative activity of a person with a high degree of freedom and self-motivation of labor activity, selforganization, self-control, awareness of personal responsibility for the process and the result of labor.

One of the problematic challenges of a modern organization is the creation of conditions for realizing innovative and creative potential of personnel as a complex of characteristics. It provides opportunities for workers to implement sustainable development of an organization, to promote economic growth on the basis of wide use of modern information technologies, knowledge and innovations. More and more often qualitative characteristics of workers that contribute to creation and implementation of creative ideas and innovation are actualized:

- continuous intellectual development, recognition of the need to acquire new knowledge, development of professional competences that define the degree of readiness for intellectual creativity and innovative practice;

- improving the system of motivation and, above all, self-motivation of labor activity, the human desire for self-actualization, realization of creative potential in professional activity, based on the boundless initiative of an individual;

- forming a creative, innovative model and attitude to work, based primarily on the principles of honesty, integrity, creativity, quality, receptivity to innovation, involvement in organisational business processes;

- the recognition of not only professional but also personal qualities of a person, their orientation, openness to new ideas, presence of healthy ambitions, life goals and ambitious plans, striving for professional and career growth, willingness to share knowledge, ideas and experience

In the basis of creative approach to training and development of professional and managerial staff there is a system of goals and values of individual and collective work. In business sphere the "theory of flow" developed by an American psychologist M. Csikszentmihalyi got exceptional popularity [9]. He is convinced that the state of creative "flow" is associated with the satisfaction and joy from the process and outcome of labor. This condition occurs when a person is fully immersed in the activity, is absolutely and genuinely involved in an individual process or a collective work. 
To achieve the state of "creative flow" specific organisational and motivational conditions are needed. They include:

- challenge by specific situation, the complexity and ambitiousness of the tasks;

- employee's ability to focus on the task at hand, to achieve the maximum concentration on the task solution;

- practical application of models of setting and achieving goals (for example, SMART, GROW etc.);

- the presence of feeling of relevance, getting benefits from the results of work, obtaining concrete results from the ongoing activities;

- total immersion of staff into the job, presence of proper working conditions and the absence of distractions;

- the ability to control the process, availability of all the necessary resources for high performance of work;

- full commitment of an employee to work, the feeling of self-forgetfulness, absorption in the process;

- psychological feeling of stopping time, subjectivity of its perception (acceleration or deceleration).

For talented, creative employees and leaders achieving the state of "flow" becomes of a particular value that is related to satisfaction of need for professional fulfillment, recognition, communication, assertiveness, high achievement, emotional tension and risk, prestige, novelty, creativity, joy and pleasure from the process and result of work, etc.

Not less interesting in terms of understanding the essence of creative management in the process of professional activity, are the views of a famous English artist, designer, teacher and business consultant R. Judkins [13]. He pays special attention to the development of creative thinking and application of creative approaches in such areas as Finance, banking, insurance, accounting, academia, management, etc. In his opinion, in these non-traditional at first glance areas to apply creativity, the use of creative approach is very often effective, it helps to reveal the creative potential of the employees and managers of an organization and leads to unexpected solutions in the process of solving professional daily problems. He stresses that creative thinking is useful in any field of activity and is able to enrich our personal and professional lives. Creative thinking can be applied to solving any problem or making any project. One of the main conditions for personal creativity development is the refusal of passivity and routine perception of reality. In his opinion, the main difference between successful innovators and those who fail lies in the commitment to "self-improvement". Successful people pay considerable attention to selfdevelopment and spend significant amounts of time on "creative improvement."

Existential and creative beginnings ensure the relevance of the cognitive approach to the training of specialists and management staff. It is focused on creating the necessary conditions for continuous professional development and leadership, professional development, taking initiative, strengthening the value of innovation in human resource management $[7 ; 8 ; 25]$.

\section{CONCLUSION}

Thus, new socio-economic reality has changed attitude to the essence of business processes, understanding the role of human resources in development of market economy. Modern organization of labor demands initiative, selfdiscipline, high motivation, direction of a personality to the system of organizational goals and values, which is based on a consumer orientation, economic and social effectiveness of professional activity, quality policy, etc. Undoubtedly, to implement such a business model both top-managers of organization and personnel should demonstrate their readiness. As we know, the most complex tasks in the sphere of organizational management are defined by necessity and importance of people's consciousness modification. The changes in thinking models, emotional state of employees, and socio-philological atmosphere require new models of organizational behavior based on confidence, openness, honesty, kindness and responsibility. Innovative thinking and innovative behavior presuppose mastering new roles. Leadership and team technologies are the daily practice in the system of effective management of human recourses.

Modern economy demands new ideas, non-standard decisions, unique approaches, which can be realized by people with high level of labor motivation, with creative and innovative potential, aimed at high results of work. Therefore, we can observe the growing interest to understanding the essence of creative management, new approaches to preparing administrative specialists. These approaches include existential, axiological, creative and cognitive approaches and they can provide high quality management in a modern organization.

\section{REFERENCES}

[1] Assen, M. Van, Berg G. Van den, Pietersma, P., (2013). Key management models. The $60+$ models every manager needs to know. FT. Prentice Hall. 2nd edition. 3d ed. Moscow: BINOM. Laboratoriya znaniy. - 319 p. ISNB 978-5-9963-1665-6.

[2] Blinov, A. O. (2012). The role of the state in organizing cognitive management. Universities for Tourism and Service Association Bulletin]. No. 1. 87-94.

[3] Blinov, A.O. (2014). The moral problem of poverty in the Russian economy. The world of new economy. No. 1. 35-41.

[4] Blinov, A.O., Lyskova, I.E. (2016). Conceptual basis of forming of ethical culture business-processes in modern organization. Journal of economy and entrepreneurship. No. 2-1 (67-1). 931-937.

[5] Blinov, A.O., Lyskova, I.E. (2016). Self-management in modern reengineering of human resources. Journal of economy and entrepreneurship. No. 3-1 (68-1). 622-626.

[6] Blinov, A. O., Rudakova O.S. (2013). Reengineering of human resources as a way competitiveness of organizations. Economy and management: problems and decisions. No. 4 (16). 62-69.

[7] Covey S.R. (2015). The 7 habits of highly effective people. Restoring the character ethics. 10 ed. Moscow: Al'pina Pablisher. - 396 p. ISNB 978-5-9614-5042-2. 
[8] Covey S.R. (2014). The $8^{\text {th }}$ habit. From effectiveness to greatness. 9 ed. Moscow: Al'pina Pablisher. - 408 p. ISNB 978-5-9614-4719-4.

[9] Csikszentmihalyi, M. (2015). Flow. The psychology of optimal experience. Moscow: Smysl, Al'pina non-fikshn. - 461 p. ISBN 9785-91671-364-0.

[10] Evans, V. (2015). Key strategy tools. The 80+ tools for every manager to build a winning strategy. PEARSON. Moscow: BINOM. Laboratoriya znaniy. -456 p. ISNB 978-5-9963-1307-5.

[11] Imai, M. (2015). Kaizen. The key to Japan's competitive success. McGraw-Hill Publishing Company. 8 ed. Moscow: Al'pina Pablisher. 274 p. ISNB 978-5-9614-5387-4.

[12] Hammer, M., Champy, J.(1993). Reengineering the corporation: a manifesto for business revolution. New York: Harper Business.

[13] Judkins, R. (2016). The art of creative thinking. Moscow: Azbuka Biznes, Azbuka-Attikus. - 432 p. ISBN 978-5-389-09458-1.

[14] Lyskova, I.E., (2014). The philosophic and sociological roots of selfmanagement. In the World of Scientific Discoveries. Human and Social Sciences. Krasnoyarsk: Publishing House Science and innovation Center. No. 7.2 (55). 757-776.

[15] Lyskova, I.E, (2015). Psychological aspect of self-management. Economic psychology: modern problems and perspective of development. Anthology of the XV International scientific-practical Conference. Sant-Petersburg. 188-194.

[16] Lyskova, I., (2015). Socio-psychological basis of self-management (historical aspect). Law, Economy and management in Modern Ambience. $4^{\text {th }}$ International Conference. 17-19 April 2015, Belgrad, Serbia. pp. $251-260$

[17] Lyskova, I., (2016). Basic principles of self-management as a technology of modern reengineering of human resources in an organization. $5^{\text {th }}$ International Conference. Application of new technologies in management and economy (ANTiM 2016). Belgrad, Serbia. V. 2. pp. 99-106.

[18] Lyskova, I., (2016). Self-management in the aspect of modern reengineering of human resources. The scientific heritage. Budapest, Hungary. V. 1. No 3 (3). Pp.7-9.

[19] Lyskova, I. Moral Concepts of Modern Business Process / International Conference on Judicial, Administrative and Humanitarian Problems of State Structures and Economical Subjects (JAHP 2016). (April 23-25, 2016. Domodedovo, Russia) Atlantis Press: Amsterdam-HongKong-Paris /http://www.atlantispress.com/php/pub.php?publication=jahp-16. Pp. 37-41.

[20] Lyskova, I. Socio-Cultural Aspect of Thriftiness / Advances in Economics, Business and Management Research, $2^{\text {nd }}$ International Conference on Economy, Management, Law and Education (EMLE 2016). (Moscow, Russia, Dec. 15-17, 2016) 2017. V. 20. P.152-154 // Atlantis Press: Amsterdam-HongKong-Paris /http://www.atlantispress.com/php/pub.php?publication=emle-16.

[21] O'Connor, McDermott, I. (2015). The art of systems thinking. Essential skills for creativity and problem solving. Thorsons. Moscow: Al'pina Pablisher. - 256 p. ISBN 978-5-9614-5289-1.

[22] Sherwood, D. (2016). Seeing the forest for the trees. A manaders's guide to applying systems thinking. Nicholas Brealey Publishing. London-Boston. Moscow: Al'pina Pablisher. - 300 p. ISBN 978-59614-5477-2.

[23] Schein, E.H. (2002). Organizational culture and leadership. SantPetersburg: PITER. - 336 p. ISBN 5-318-00573-X.

[24] Marr, B.(2014). Key performance indicators. The 75 measures every manager needs to know. PEARSON. Moscow: BINOM. Laboratoriya znaniy. - 340 p. ISNB 978-5-9963-1635-9.

[25] Maxwell, J.C. (2013) The 5 levels of leadership (Proven steps to maximize your potensial. Minsk: Popurri. - 320 p. ISBN 978-985-15$1857-5$. 